\title{
XXXIII. The distribution of the actinic sunlight on the Northern Hemisphere at summer solstice
}

\author{
John Sebelien
}

To cite this article: John Sebelien (1905) XXXIII. The distribution of the actinic sunlight on the Northern Hemisphere at summer solstice, Philosophical Magazine Series 6, 9:51, 351-360, DOI: $10.1080 / 14786440509463286$

To link to this article: http://dx.doi.org/10.1080/14786440509463286

曲 Published online: 15 Apr 2009.

Submit your article to this journal $\sqsubset$

Џ Article views: 2

Q View related articles $\square$ 


\section{[ $\begin{array}{ll}351 & ]\end{array}$}

XXXIII. The Distribution of the Actinic Sunlight on the Northern Hemisphere at Summer Solstice. By JоHN Sebrilien *.

THE distribution of the effect of the solar radiation over the different regions of the globe and at different seasons has often been subject to calculation, and attention has often been directed to the favourable position of places at high latitude during summer-time.

The laws of the intensity and quantity of solar radiation are said to have been examined for the first time by Halley in 1779 , later determined by Plane + . Chr. Wieler $\ddagger$ published in 1879 a series of curves, showing the relative intensity of the solar radiation during its yearly periods and at various seasons for every tenth degree of latitude. His results were not corrected for atmospheric absorption, which varies for rays of different refrangibility. The calculations of Wieler show that on the 21st of June the radiation that reaches unit area of the surface of the globe during 24 hours has its maximum value at the North Pole. The relative values of the said radiation at $0^{\circ}, 60^{\circ}, 75^{\circ}$, and $90^{\circ} \mathrm{N}$. lat. are as $282: 350: 362: 385$. The North Pole keeps its superior position not only on that single day but also during the whole period from 5th of May till the 7th of August (the longitude of the sun increasing from $45^{\circ}$ to $135^{\circ}$ ). If the total radiation during this period is calculated, its values at $0^{\circ}, 40^{\circ}, 60^{\circ}$, and $90^{\circ} \mathrm{N}$. lat. are as $710: 886: 846: 896$. This shows a secondary maximum at about $40^{\circ}$, while the absolute maximum is at $90^{\circ} \mathrm{N}$. lat.

The researches of Langley on the atmospheric absorption of rays of different refrangibility having cleared this question, Spitaler \& calculated the quantity of sunlight reaching a unit of area for each 10th degree of latitude during an average day for each of the twelve months of the year. For this caleulation he assumed a coefficient of absorption $0 \cdot 6$, corresponding to the rays of an average refrangibility in the yellow-green part of the spectrum. The results found by Wieler, neglecting the influence of the atmosphere, were now so far modified that the maximum value of the daily quantity of sunlight at midsummer does not fall on the North Pole. Spitaler finds that for a day of June the maximum radiation is at $30^{\circ} \mathrm{N}$. lat. The quantity of light

* Communicated by Sir H. E. Roseoe, F.R.S.

+ Comptes Rendus, t. 1viii. 1864.

\pm Zeitschrift für Meteorologie, 1879, p. 114.

$\$$ Eder's Jahrbuch fiir Photographie, etc. 1888, Bd. xi. p. 377. 


\section{Prof. J. Sebelien on the Distribution of Actinic Sunlight}

diminishes towards the equator as well as towards $70^{\circ} \mathrm{N}$. lat.; from here it increases again, and reaches at $90^{\circ}$ a secondary maximum that, however, has a smaller value than that quantity of light which on the same day reaches the regious of $60^{\circ} \mathrm{N}$. lat.

But even the results of Spitaler are incomplete, since his calculations only refer to the direct insolation, without regard to the diffused daylight. Moreover, those calculations are of a purely theoretical nature, without the support of any experiment. In the fifties Bunsen and Roscoe made their famous photochemical researches * of the light influencing the chlorine and hydrogen explosive mixture. These experimenters found that the said activity is especially localized between the lines $\mathrm{G}$ and $\mathrm{M}$ of Fraunhofer in the solar spectrum; from here it decreases more quickly and regularly towards the red end of the spectrum than towards the ultra-violet one. Their researches showed, further, that whe sun-rays, before entering the atmosphere, have a photochemical effect of 35.5 light-metres, that is, by complete absorption in an infinite atmosphere of chlorine-hydrogen electrolytic gas at $760 \mathrm{~mm}$. pressure and $0^{\circ} \mathrm{C}$., they will be able to transform during a minute a column of the said mixture of 35.5 metres height into hydrogen chloride. Having passed through the atmosphere, the sun-rays on reaching the surface of the ocean will only possess a photochemical effect of 14.4 light-metres; thus, in passing the atmosphere they will have lost about two-thirds of their photochemical effect.

Bunsen and Roscoe generally express the effects of light that they measured and calculated in chemical photo-units, each one of which is determined by the chemical action upon a normal explosive mixture of hydrogen and chlorine contained in an insolation vessel of such small dimensions that the variability of the extinction appearing in large vessels may be neglected when the said explosive gas is illuminated at a distance of 1 metre from a so-called normal flame, that is, a flame of burning carbonic oxide at a certain pressure issuing from a platinum burner of accurately determined dimensions. 10,000 of these photo-units are called 1 chemical light-unit.

The sun-rays reaching a horizontal area of the surface of the earth at an angle $\phi$ with the vertical will produce in one minute on each square unit of this area a photochemical effect that may be expressed in chemical light-units by the formula

$$
\mathrm{W}=318 \cdot 3 \cdot \cos \phi \cdot 10^{-\frac{0 \cdot 4758 \mathrm{P}}{\cos \phi}}, . .
$$

* Pogggendorff's Annalén, Bd. xcri. \&c.; Ostwald's Klassiker Auşahen, Bd. xxxiv. \& xxxviii. 
on the Acothitin Hemisphere at Summer Solstice.

$\mathrm{P}$ denoting the atmospherical pressure, and the constant 318.3 corresponding to the photochemical intensity of the sunlight at the uppermost limit of of the atmosphere, while the constant 0.4758 denotes the atmospherical extinction of the direct solar light (Poggendorff's Annalen, Bd. criii. p. 257 ; Ostwald's Klassike? Ausgallen, No. 38, pp. 90, 91). Developing in a series with increasing power's of $\cos \phi$, and calculating the coefficients by means of the method of least squares, Bunsen and Roscoe transformed the said formula to

$$
W \equiv 31.99 \cos ^{2} \phi+417 \cdot 6 \cos ^{3} \phi-248 \cdot 7 \cos ^{4} \phi . .
$$

To get the chemically active * quantity of light falling upon a horizontal element of the surface of earth for a whole day, we may substitute

$$
\cos \phi=\cos \delta \cos p \cos t+\sin \delta \sin p,
$$

$p$ denoting the latitude, $\delta$ the declination of the sun, and $t$ the lour angle of the sun. Then we may calonlate the integral

$$
W=\int_{-t_{1}}^{t_{2}} w d t
$$

where $t_{1}$ and $-t_{1}$ denote the hour angle of the sun at sunset and at sunrise respectively on the day in question.

For the sake of shortness put

$$
\sin \delta \sin p=\alpha \text { and } \cos \delta \cos p=\beta \text {, }
$$

when the quantity under the integral may be written

$$
\left.\begin{array}{r}
w=31 \cdot 99\left(\alpha^{2}+2 \alpha \beta \cos t+\beta^{2} \cos ^{2} t\right) \\
+417 \cdot 6\left(\alpha^{3}+3 \alpha^{2} \beta \cos t+3 \alpha \beta^{2} \cos ^{2} t+\beta^{3} \cos ^{3} t\right) \\
-248 \cdot 7\left(\alpha^{4}+4 \alpha^{3} \beta \cos t+b \alpha^{2} \beta^{2} \cos ^{2} t+4 \alpha \beta^{3} \cos ^{3} t\right. \\
\left.+\beta^{4} \cos ^{4} t\right)
\end{array}\right)
$$

At the equinoxes, when $\alpha=0, \beta=\cos p$, and the integration is to be performed between the limits $t=-\frac{\pi}{2}$ and $t=+\frac{\pi}{2}$, the said integral will attain a very simple form. Bunsen and Roscoe calculated it to

$$
\mathrm{W}=-11520 \cos ^{2} p+127600 \cos ^{3} p-67140 \cos ^{4} p .
$$

Bunsen and Roscoe further determined the photochemical effect of the light reflected from a cloudless sky. They

* By chenical action we understand hereafter ouly the action on the explosive mixture of chlorine and hydrogen.

Phil. Mag. S. 6. Vol. 9. No. 51. March 1905. 2 A 
354 Prof. J. Sebelien on the Distribution of Actinic Sunlight

found that the effect upon a horizontal element of the surface of the earth in one minute may be expressed in chemical light-units by the zenith-distance of the sun $\phi$ according to the formula

$$
w_{1}=2 \cdot 77 b^{\circ}+80 \cdot 849 \cos \phi-45 \cdot 996 \cos ^{2} \phi .
$$

For a larger interval of time, in which the hour angle of the sun is assumed to grow from $t_{1}$ to $t_{2}$ (expressed in minutes of arc), the total photochemical effect in light-anits will be

$$
\mathrm{W}_{1}=\frac{12 \times 60}{\pi} \int_{-t_{1}}^{t_{1}} w_{1} d t
$$

This integration may be executed with the same substitutions as above, and will then give the formula

$$
\begin{aligned}
\mathrm{W}_{1}=\frac{24 \times 60}{\pi}[ & {\left[2.776+80.849 \alpha-45.996\left(\alpha^{2}+\frac{\beta^{2}}{2}\right)\right] t_{1} } \\
& +\left(80.879 \beta-\frac{3}{2} \times 45.996 \alpha \beta\right) \sin t . \quad .
\end{aligned}
$$

Even this expression will be simplified for the equinoxes, as Bunsen and Roscoe themselves pointed out. Putting $\delta=0, \alpha=0, \beta=\cos p, t=\frac{\pi}{2}$, the formula (2) is transformed to

$$
W_{1}=1998 \cdot 8+37058 \cos p-16559 \cos ^{2} p .
$$

By means of these formulæ Bunsen and Roscoe have cal culated for a series of localities the total quantity of actinic light expressed in light-units which in the course of the day of equinox falls upon a horizontal element of surface in the form of direct solar radiation as well as in the form of reflected daylight. These numbers are reproduced in the following Table I., where I have calculated the numbers marked with an asterisk, which are not given in the original table of Bunsen and Roscoe.

This shows the extent to which the diffused daylight tends to equalize the numbers for the total quantity of light at the different latitudes. While the daily quantity of light due to direct radiation is forty times as great at the equator as it is at the pole, the quantity of diffused daylight is hardly twice as great at the equator as at the pole on the same day. Further, the numbers in Table I. show that while at the equator the effect of the direct insolation on the said day has double the value of the daily effect of the diffused daylight, these numbers will become equal in the neighbourhood of 
$49^{\circ} \mathrm{N}$. lat., and the further we get towards the north, the more the diffused daylight will dominate.

Table I.

\begin{tabular}{|c|c|c|c|c|}
\hline & $p$ & $\begin{array}{c}\text { W. } \\
\text { Direct } \\
\text { radiation. }\end{array}$ & $\begin{array}{l}\text { W. } \\
\text { Diffused } \\
\text { daylight. }\end{array}$ & $w+w_{1}$ \\
\hline & N. lat. & Light-units. & Light-units. & Light-units. \\
\hline 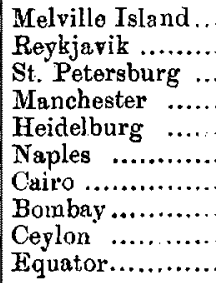 & 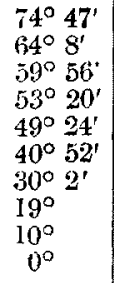 & $\begin{array}{r}1196 \\
5964 \\
8927 \\
14520 \\
18240 \\
23640 \\
36440 \\
43820 \\
47530 \\
48940\end{array}$ & $\begin{array}{l}10590 \\
15020 \\
16410 \\
18220 \\
19100 \\
20550 \\
21670 \\
22234 * \\
22435 * \\
22498 *\end{array}$ & $\begin{array}{l}11790 \\
20980 \\
25340 \\
32740 \\
37341 \\
47190 \\
58110 \\
66054^{*} \\
69965 * \\
71438^{*}\end{array}$ \\
\hline
\end{tabular}

The preference conferred upon the northern latitudes with regard to their actinic illumination at the equinoxes will increase with the declination of the sun, and reaches its maximum value at the summer solstice.

By means of the above-mentioned formula of Bunsen and Roscoe I have calculated the quantity of actinic light which on the midsummer-day falls upon a horizontal element of surface from sunrise to sunset for every tenth (or fifth) degree of latitude.

On the said day we shall have in formula (1)

$$
\begin{gathered}
\alpha=\sin 23^{\circ} 27^{\prime} \sin p ; \quad \beta=\cos 23^{\circ} 27^{\prime} \cos p ; \\
\cos t=\tan 23^{\circ} 27^{\prime} \tan p,
\end{gathered}
$$

and putting the constants

$$
a=31 \cdot 99, \quad b=417 \cdot 6, \quad a=248 \cdot 7,
$$

the integration will give

$$
\begin{aligned}
& \int_{-t}^{+t} w d t=2 \mathrm{~A} t+2 \mathrm{~B} \sin t+\mathrm{C}(\sin t \cos t+t) \\
& +2 \mathrm{D} \frac{\cos ^{2} t \sin t+2 \sin t}{3}+\Sigma \frac{2 \cos ^{3} t \sin t+3 \cos t \sin t+3 t}{4}
\end{aligned}
$$


356 Prof. J. Sebelien on the Distribution of Actinic Sunlight

where

$$
\begin{aligned}
& \mathrm{A}=\alpha^{2}\left(a+b \alpha+c \alpha^{2}\right), \\
& \mathrm{B}=\alpha \beta\left(2 a+3 b \alpha+4 c \alpha^{2}\right), \\
& \mathrm{C}=\beta^{2}\left(a+3 b \alpha+6 c \alpha^{2}\right), \\
& \mathrm{D}=\beta^{3}(b+4 c \alpha), \\
& \mathrm{E}=c \beta^{4} .
\end{aligned}
$$

Introducing in this expression various values of $p$ we get the values for the actinic direct sunlight, put in the column $\mathrm{W}$ of Table II.

The values for the diffused light, which we have put in the column $W_{1}$ of Table II., we have calculated in a similar way by means of the formula (2), where the quantities $\alpha, \beta$, and $t$ take the same values as in the calculation of the values of $W$.

The sum of $W$ and $W_{1}$ for each latitude is found in the last column of the table, and shows the total amount of the

\begin{tabular}{|c|c|c|c|}
\hline N. lat. & $\begin{array}{c}\text { Direct } \\
\text { insolation, W. } \\
\text { Light-mnits. }\end{array}$ & $\begin{array}{c}\text { Diffused } \\
\text { daylight, W. } \\
\text { Light-units. }\end{array}$ & $\begin{array}{l}\text { Total light, } \\
W+W_{1} \text {. } \\
\text { Tight-units. }\end{array}$ \\
\hline 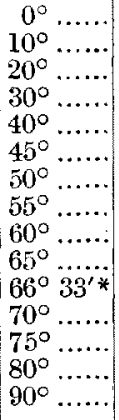 & $\begin{array}{c}60656 \\
70891 \\
77703 \\
89060 \\
79644 \\
76178 \\
72584 \\
62704 \\
62064 \\
57089 \\
54573 \\
50267 \\
44587 \\
40080 \\
36211\end{array}$ & $\begin{array}{l}22060 \\
23388 \\
24539 \\
25775 \\
27059 \\
27757 \\
28521 \\
28589 \\
30484 \\
32168 \\
33264 \\
35012 \\
37099 \\
38612 \\
39859\end{array}$ & $\begin{array}{r}82716 \\
94479 \\
102242 \\
114835 \\
106701 \\
103935 \\
101105 \\
91293 \\
92548 \\
89257 \\
87837 \\
85279 \\
81686 \\
78700 \\
76048\end{array}$ \\
\hline
\end{tabular}
actinic light.

TABLE II.

Chemical Light-units pr. Unit Horizontal Area on

Midsummer-day.

* The northern polar circle.

Fig. 1 gives a graphical representation of these numbers. The lower dotted curve shows the variation of the diffused daylight. We see that at the lower and middle latitudes 
on the Northern Hemisphere at Summer Solstice. $\quad 35$ '

the curve rises rather smoothly and slowly; at about $55^{\circ} \mathrm{N}$. lat. the curve begins to get steeper with the concavity upwards, and at the highest latitudes again it turns more flat with a downward concavity. The situation of turning-point for which $\frac{\partial^{2} W}{\partial p^{2}}=0$ seems from the figure to be near $p=70^{\circ} \mathrm{N}$. lat.

FIG. 1.-Distribution of the violet and ultraviolet light (actinic on an explosive mixture of hydrogen and chlorine) at summer solstice at different Latitudes.

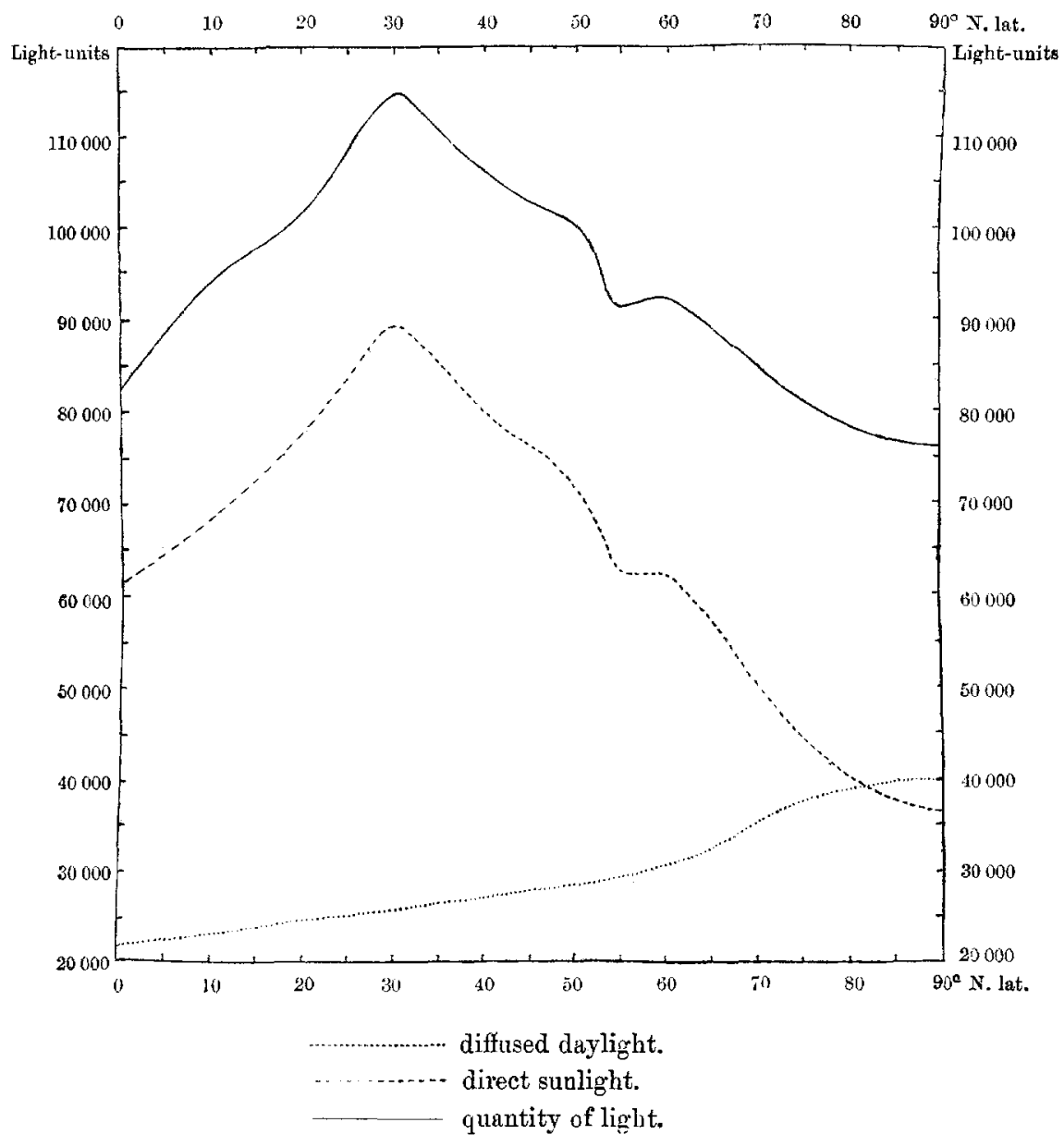




\section{Prof. J. Sebelien on the Distribution of Actinic Sunlight}

The middle eurve, that indicates the distribution of the actinic light from direct radiation over various latitudes, shows quite another appearance. Starting from $0^{\circ} \mathrm{N}$. lat., the curve rises quickly and reaches its maximum value at $30^{\circ} \mathrm{N}$. lat. From here it decreases fast, but irregularly, towards the pole, changing its concavity several times. We see, for instance, that at $40^{\circ} \mathrm{N}$. lat. there is a small upward concavity, at $50^{\circ}$ a somewhat larger upward convexity. Between $50^{\circ}$ and $60^{\circ}$ we find again a very strong upward concavity, the curve completely ceasing to fall, and continuing about horizontally from $56^{\circ}$ to $60^{\circ}$, that is, on a strip bordered on the south by a line traversing the northern part of Vancouver Island, the north of Newfoundland, Newcastle, the south of Fünen, and Zeeland, and on the north by a line through the southern point of Greenland, Christiania, Upsala, and St. Petersburg. From here the curve decreases again towards the higher latitudes, at last showing a marked upward concavity. At the said range from $56^{\circ}$ to $60^{\circ}$ the direct insolation on midsummer-day is on the whole as large as at the equator on the same day.

While the quantity of diffused chemical light at the North Pole on the said day is about double the quantity at the equator, the quantity of directly insolated chemical light has at the equator abont double the value that it has at the North Pole, and at $30^{\circ} \mathrm{N}$. lat. (for instance, the Canary Islands, Suez, New Orleans, Shanghai) its value is about three times as great as at the North Pole.

The value of the directly insolated chemical light (at $30^{\circ}$ $\mathrm{N}$. lat.) is on the said day more than twice the maximum value of the diffused chemical light (at $90^{\circ} \mathrm{N}$. lat.), but at the North Pole the quantity of the diffused daylight (not chemical activity) will surpass the directly insolated light by about 4000 chemical light-units. At $82^{\circ} \mathrm{N}$. lat. the quantities of diffused daylight and of direct solar light are equal, viz., 31,000 light-units.

The upper full-drawn curve of the figure shows the distribution of the total quantity of chemical light $\left(W+W_{1}\right)$. The aspect of this curve is obviously stamped by the curve for the direct insolation. However, the diffused daylightthat especially towards the north-is also greatly asserting itself. Although the total quantity of light according to this curve has still its maximum value at $30^{\circ} \mathrm{N}$. lat., and the North Pole still receives less light than the equator, yet the difference between the extremes is levelled considerably. A spot at the equator receires at midsummer-day only a total quantity of 6000 chemical light-units more than the 
on the Northern Hemisphere at Summer Solstice.

North Pole, and at $30^{\circ} \mathrm{N}$. lat. the total quantity of chemical light bas not quite twice the value it has at the pole. Add to this, that at $73^{\circ} \cdot 5 \mathrm{~N}$. lat. (that is, more northerly than the north of Norway) the total quantity of chemical light is as great as at the equator, and further, that for a strip from $55^{\circ}$ to $73^{\circ} 5 \mathrm{~N}$. lat. the daily quantity of light on the said day is as great as for an equatorial range to about $7^{\circ} \mathrm{N}$. lat. When we go towards the north from the 55th degree of latitude the total quantity of chemical light will increase by some thousands of light-units until a secondary maximum at $60^{\circ} \mathrm{N}$. lat. is reached. A very great decrease of about 10,000 chemical light-nnits, or about one-eighth of the total quantity of light at the equator, having taken place from $50^{\circ}$ to $55^{\circ} \mathrm{N}$. lat., there appears once more an increase of the quantity of light for a range reaching from the south coasts of the larger Danish isles to the Norwegian town Kristianssund. From here the quantity of light decreases further, but does not within the Scandinavian peninsula attain as low a value as at the equator. Even for the northern part of Scandinavia $\left(70^{\circ} \mathrm{N}\right.$. lat. $)$ the total quantity of chemical light on midsummer-day is not less than 80 per cent. of its maximum value at $30^{\circ} \mathrm{N}$. lat.

We have thus shown that the northern parts of the globe, with regard to the chemical light that they receive at midsummer-time under a perfectly pure and cloudless atmosphere, are much more fortunately situated than we should have expected from the relative numbers in the table of Spitaler. According to these, we should find that the quantity of light on a day of June at $70^{\circ} \mathrm{N}$. lat. would be $\frac{280}{481} \cdot 100=58$ per cent. of the quantity of light on the same day at $30^{\circ} \mathrm{N}$. lat., where we have the maximum even according to Spitaler. In other respects, too, there are essential differences between the numbers calculated from the formulm of Bunsen and Roscoe and those of Spitaler. Thus we do not find in the numbers for the actinic light that increase of the quantity of light that according to Spitaler should take place from $70^{\circ}$ to $90^{\circ} \mathrm{N}$. lat.

As we have already mentioned, we have only referred here to that part of the sunlight that produces the well-known effect on the explosive mixture of hydrogen and chlorine. The said effect has its maximum value in the spectral range $\frac{1}{3} \mathrm{GH}-\mathrm{H}$, and is produced chiefly by the violet and ultraviolet rays.

The effect of the direct sunrays of other wave-lengths is 
illustrated by the formulæ given by M. Andresen*, and similar to the formula above (a), viz., for the spectral fraction between the lines $F$ and $G$ blackening silver-chloride paper,

$$
\mathrm{W}=4715 \times 10^{-\frac{0298 \mathrm{P}}{\operatorname{ens} \phi}} \text {. }
$$

The sunrays passed through a solution of auramine-O, that is, the spectral fraction situated about the line $D$, produce an effect on a silver-bromide paper that is sensitized with rhodamine-B, expressed by the formula

$$
W=1663 \times 10^{-\frac{0 \cdot 109 \mathrm{P}}{\cos \emptyset}}
$$

and the effect of the red rays, which are sitmated on the other side of $\alpha \frac{2}{5} \mathrm{D}$ (wave-length $610 \mathrm{j}$ is measured by a silver-bromide paper sensitized with a solution of chlorophyll, and is expressed by

$$
\mathrm{W}=445 \times 10^{-\frac{0 \cdot 117 \mathrm{P}}{\cos \bar{\phi}}} .
$$

These formula may also be expanded in a series of increasing powers of $\cos \phi$, and will then give expressions similar to the formula $(b)$, which may be integrated with regard to $t$. Those curves giving the distribution of the directly shining sunlight of the less refrangible spectral regions will be of the same nature as the one we have found for the more refrangible light, but they will not be equidistant, and their special points w ill probably not all correspond to the same latitudes.

Chemical Laboratory,

Royal Norwegian Agricultural College, Aas, near Kristiania.

XXXIV. Unrecognized Factors in the Transmission of Guses: through Water. By W. E. Aleney, D.Sc., Curator and Examiner in Chemistry in the Royal University, Dullin $\uparrow$.

THE question of the possibility of atmospheric gases being transmitted through water by any process other than that of diffusion, or by thermal currents, or mixing, does not appear to have been considered.

Hüfner $\$$ found, in his work on the diffusion coefficients of gases in water, that, if a gas be placed above the liquid, the phenomenon of diffusion is disturbed by downward

* Eder's Jahrbuch fuir Photographie etc. xiii. 1899, p. 149.

† Communicated by the Author. (Reprinted from Trans. Roy. Dubl. Soc. : read Dec. 20, 1904.)

† Ann. Phys. Chem. (11) vol. 1x. pp. 134-168 (1897). 